\title{
Corporate Digital Responsibility
}

\section{Relevance and Opportunities for Business and Information Systems Engineering}

\author{
Cristina Mihale-Wilson • Oliver Hinz $\cdot$ Wil van der Aalst $\cdot$ Christof Weinhardt
}

Published online: 1 March 2022

(c) The Author(s), under exclusive licence to Springer Fachmedien Wiesbaden GmbH 2022

\section{Introduction}

Advancements in fundamental technologies such as Artificial Intelligence enable a new generation of digital products and services. This new generation of digital products and services is more intelligent, complex, and autonomous than ever before (Baird and Maruping 2021). It can adapt to various contexts to better fit the needs of the user. Further, the new generation of products and services can easily be combined with other technologies and vast amounts of data to create even more sophisticated and complex digital products and service networks. Thus, the new generation of products and services can significantly improve individuals' lives and generate unique business opportunities. At the same time, it can also instigate novel ethical, legal, and social issues (Berente et al. 2021). Within this context, the concept of Corporate Digital Responsibility $(C D R)$ has emerged.

C. Mihale-Wilson $(\bowtie) \cdot$ O. Hinz

Chair of Information Systems and Information Management, Goethe University Frankfurt, Theodor-W.-Adorno-Platz 4, 60323 Frankfurt am Main, Germany

e-mail: mihale-wilson@wiwi.uni-frankfurt.de

O. Hinz

e-mail: ohinz@wiwi.uni-frankfurt.de

W. van der Aalst

Lehrstuhl Für Informatik 9, RWTH, Ahornstr. 55,

52056 Aachen, Germany

e-mail:wvdaalst@pads.rwth-aachen.de

\section{Weinhardt}

Institute of Information Systems and Marketing (IISM),

Karlsruhe Institute of Technology (KIT), Kaiserstr. 89-93,

76133 Karlsruhe, Germany

e-mail: weinhardt@kit.edu
CDR articulates companies' extended responsibilities regarding the new opportunities and challenges that technology development and use can bring (Herden et al. 2021). At its core, $C D R$ is related to Corporate Social Responsibility (CSR). In essence, both concepts summarize the obligations that companies have toward society. Moreover, both concepts aim at minimizing the adverse effects of practice activities while maximizing the benefits of a firms' activities. Given these similarities, two legitimate questions arise: Why do we need CDR in addition to CSR? Does not the established CSR concept cover CDR as well?

As a corollary of these questions, there are two possible views on CDR: On the one hand, we can view CDR as an extension of CSR and argue that CDR reflects, in essence, similar social and sustainability responsibilities as CSR (Herden et al. 2021). On the other hand, there are also various compelling reasons for perceiving CDR as a separate albeit interrelated concept to CSR (Elliott et al. 2021; Lobschat et al. 2021). Without aiming to lead a conclusive discussion and final verdict on whether CDR is an extension to CSR (Herden et al. 2021) or a distinct concept (Elliott et al. 2021; Lobschat et al. 2021), in the following, we present various reasons why we should bestow separate research efforts on CDR.

\section{Why is There a Need for CDR in Addition to CSR?}

Debates on what responsibilities companies have towards society are not new and date back to the early ' $50 \mathrm{~s}$, where CSR envisioned that business executives make decisions according to society's values (Agudelo et al. 2019). Since then, CSR has constantly evolved to reflect changes in societal concerns and expectations, to match impactful 
events and trends (e.g., globalization), or the emergence of (supranational) organizations promoting eco-sustainability (e.g., the United Nations Development Program).

A common perspective on CSR is that it is about fulfilling the company's obligations towards its stakeholders. In fulfilling these obligations, harm should be minimized while beneficial long-term impacts of the firm on society should be maximized (Smith 2001). Although this same basic idea is also at the core of CDR, it is notable that CSR is concerned with business practice accountability in general, while CDR is mainly focused on responsibility in relation to developing and using technology.

Admittedly, since CSR has historically evolved (Agudelo et al. 2019), it is theoretically possible that it will evolve further to accommodate changes in social expectations regarding technology development and use. However, even if this were the case, the CSR concept would likely remain too broad to do justice to the importance and complexities of technology. Because technologies such as AI have various characteristics that reshape value creation and the relationship between companies and society, it is expedient to make separate efforts to identify the new social responsibilities of developing and operating such technologies. Agency (i.e., ability to act as an autonomous entity), recombinant capabilities, pervasiveness, and opacity are only a few examples of the characteristics that challenge all levels of traditional corporate responsibility in a significant manner. To better understand how the characteristics mentioned above are reshuffling traditional responsibilities, here are a few examples:

According to Carroll (1991), companies traditionally have social responsibility on four levels: economic, legal, ethical, and philanthropic. On the economic level, which represents the foundation for the other responsibilities in the pyramid, companies are expected to be (economically) successful. The pervasiveness of technology, for instance, opens up various ways for companies to generate profits. However, these profits might be at the cost of privacy. Technologies can track every move, any time and everywhere, thereby gathering vast amounts of data on individuals and their activities (van der Aalst et al. 2017; Elliott et al. 2021). While this data allows for new business models and cost savings through optimized and automatized processes, it also creates concerns about irresponsible data use. Accordingly, the development and use of technology intensifies the trade-off between consumers' privacy and maximizing financial benefits through collecting consumer data.

Furthermore, since digital products and services can be replicated at a very low marginal cost, monopolies can form. In such markets, tech giants skim off most of the profits while leaving little chances for competitors to make profits and challenge the status quo. Related to the emergence of monopolies, it is notable that technology also challenges the philanthropic responsibilities of corporations. As Carroll (1991) suggests, corporations should be good citizens and try to improve the quality of life of society (Herden et al. 2021). However, the existence of monopolies improves the life of only few within society.

Also, the recombinant capabilities of various technologies challenge existing corporate responsibilities. Recombinant capabilities enable the formation of robust business networks and digital ecosystems for improved value creation. Although such networks can be highly valuable, the opacity of various technology components, combined with intransparent data collection and processing, complicate the measurement and fair distribution of profits for the various business partners.

Additionally, the agentic nature of the new generation of systems and services challenges the ethical and legal level of corporate responsibilities. From an ethical perspective, business executives should make decisions according to the values of society. Yet, with the new generation of systems that are malleable and can be autonomously acting entities (Baird and Maruping 2021), how can we ensure that their decisions are aligned with society's values? After all, various scholars have pointed out that automated decisionmaking has a black-box character (Elliott et al. 2021) and can be unfair (van der Aalst et al. 2017).

Moreover, system and system networks that entail dynamic and agentic components incur unprecedented and hitherto unsolved liability issues that need to be dealt with. On the legal level, companies must adhere to the laws and regulations of their markets. However, because technological progress is faster and results in more complex artifacts than ever, regulation lags behind the current developments. Agentic and malleable individual components within system networks, for instance, make it increasingly challenging and sometimes impossible to conclusively identify the one component within the network that has led other components to malfunction. This, in turn, makes any regulation of liability claims nearly impossible.

The exemplary arguments from above highlight that a distinction between CDR and CSR is necessary because technology reshapes and extends the traditional corporate responsibilities unprecedentedly. Due to the complexity that technology adds to corporate responsibility and the fact that managing the consequences and opportunities that technologies can bring about requires a strong technological focus, it seems appropriate to view CDR as distinct from CSR.

In essence, the main difference between CDR and CSR is given by the role that technology plays in the respective concept. While CSR has a relatively broad goal towards society that affords technology only subordinate 
importance, CDR revolves around technology and its implications for corporations and society. Besides these main differences between CDR and CSR, there is no clear cut between the two concepts, so that thematic overlaps are possible (Lobschat et al. 2021).

Overlaps between the two concepts can occur with regard to various topics, ranging from eco-efficiency and working conditions to human rights and social equity. Just as an example, there might be an overlap between CDR and CSR concerning the environmental sustainability of technologies. After all, technology and digitalization require vast amounts of energy and various natural resources. This is especially true for the construction of hardware (e.g., processors, computers, smartphones) and diverse network and data center infrastructure, but also for operating computationally intense systems and distributed ledger technology (Kröhling 2017). Both concepts, CDR and CSR, will very likely address this key issue. However, they will probably do so using different perspectives and approaches. In this regard, we expect CSR to tackle the topic by focusing on the strategic and managerial actions that could ensure improved energy management. In contrast, CDR will approach the issue through possible architecture choices, implementation guidelines and best practices that can lead to an energy-saving design and operation of technology systems.

\section{The Status Quo of CDR}

To date, numerous practice-related or governmental initiatives have evolved around CDR. For example, supranational organizations like the European Union, the OECD, or the UN have developed guidelines and regulations to address various challenges that technologies and digitalization involve. There are also several working groups that try to establish CDR in the corporate mindset. Additionally, we can observe national and industry-led initiatives (e.g., the German 'Corporate Digital Responsibility Initiative') where industry leaders want to set a good example by committing to ethical business practices in the digital world. Within this practice-driven debate, experts have identified various areas as a basis for ethical and responsible digital business practice. Amongst others, experts agree that companies should ensure that everyone has access to essential digital goods, that everyone knows how to use these goods and everyone is aware of the repercussions of their consumption behaviour. Additionally, experts suggest that there should be increased transparency of algorithmic decisions, data flows, or data privacy and security breaches (Nofer et al. 2014). Likewise, experts highlight the importance of safety and liability in the digital world, along with appropriate governance and participation mechanisms to ensure compliance with rules and regulations (Mihale-Wilson et al. 2021).

In parallel to the practice-driven debate on CDR, academic interest in CDR is also slowly growing. To accelerate and intensify the resonance of the topic in the IS community, we wish to highlight the relevance and research opportunities that CDR can offer to our discipline.

\section{Relevance of CDR for BISE Community}

There are various compelling reasons why the BISE community should be at the forefront rather than mere bystanders to how various governmental and practice-driven initiatives shape and define the concept of CDR. In this regard, we note that the BISE community has an inherent obligation and the necessary aptitude to advance the establishment of CDR in organizations significantly.

The community's obligation to actively engage in the CDR discourse stems from the fact that technology and digital goods are at the core of our research discipline. Given that technology creates both challenges and opportunities that need to be managed, research on how to maximize (minimize) the positive (adverse) effects of technology should be just as much part of our research focus as other research topics established in BISE.

Further, another good reason to actively engage in CDR research is the reciprocal relationship between IS research and practice. On the one hand, IS research has a long-term history in researching technology's design, deployment, and its subsequent implications (Watson et al. 2010; Legner et al. 2017). Admittedly, to date, companies' efforts to alleviate adverse effects of technology use are voluntary. However, because of various public, competitive and industry-specific factors, all organizations will sooner or later feel the pressure to engage in CDR activities (Lobschat et al. 2021). Accordingly, we expect that CDR will shortly very likely become at least as relevant as CSR. If this is the case, it is in line with the BISE research focus to start researching the new but highly practice-relevant topic of CDR.

On the other hand, through its research, the BISE community regularly influences various organizations and businesses (Watson et al. 2010). As the BISE community traditionally addresses topics of practical relevance and carries essential findings from its research back into practice (Legner et al. 2017), actively engaging in CDR research will allow the BISE community to provide guidance for organizations to meet and solve social and ethical dilemmas (Lobschat et al. 2021). After all, although information systems and other digital products are designed with the best of intentions, they can still maintain or reinforce issues such as unfairness or discrimination 
(Feuerriegel et al. 2020). Thus, it is in line with the BISE research focus to investigate how information systems and other digital products can be designed and used without any adverse consequences.

Ultimately, due to the long history of the community in researching the design and exploitation of technology for various purposes, the BISE community is particularly suited to guide companies towards socially and ethically sound technology systems. Notably, the CDR concept envisions ethical and social business practices on all levels of the organization. Hence, CDR can be implemented on the management level or in a company's mission statement. Alternatively, it can also reflect in the use of technology or digital products and services design. While management scholars may research CDR from a managerial perspective, the BISE community is particularly suited to investigate the operationalization of CDR on the technology and product level.

\section{Opportunities for BISE Research}

Besides the aforementioned reasons why the BISE community should actively engage in conducting CDR-related research, we also argue that engaging in this highly practice-relevant topic at this point will generate new research opportunities and collaborations with organizations.

As mentioned previously, the CDR debate is currently strongly driven by practice. Within this debate, practitioners suggest various rules and norms that companies should follow towards establishing suitable corporate practices for the digital world. Although some suggestions made within this debate are plausible and feasible (e.g., consumers should be informed about the usage of their data), others are too vague to be directly implemented (e.g., consumers' economic interests should be protected). This opens up new opportunities for our discipline. After all, IS has a proven track record for developing concepts that are implementable in practice.

To date, practice-driven suggestions are not mature and concrete enough to allow companies to implement CDR into daily business. However, if CDR is genuinely supposed to catch on in day-to-day business, organizations require concrete and comprehensive frameworks or action plans with actionable insights that are well understood and have proven effective. This is where the BISE community experience comes into play and will be instrumental in conceptualizing and articulating meaningful ways to implement CDR in various companies.

Also, besides the plausibility, feasibility, and concreteness of various suggestions stemming from the practicedriven CDR debate, there is currently no concrete indication of the suitability and effectiveness of various CDR strategies in practice. However, since companies traditionally operate with limited resources, the adoption of CDR in daily business hinges on understanding which CDR measures impact which type of company to what extent and with what outcome. Against the background that only rigorous, structured investigations can measure and establish the suitability and effectivity of the CDR measures and suggestions put forward by practice, various potentially fruitful research paths open up for the BISE community.

Besides, the emergence of the CDR concept opens different research paths that allow the BISE community to engage in inter-disciplinary and impactful research. Because the concept of CDR touches on various levels of the organization, holistic perspectives on how CDR can be adopted in practice require inter-disciplinary efforts with other scholars, for instance, from management, business ethics, or sociology. By working closely with scholars from other disciplines, the BISE community can help generate holistic and actionable insights for regulators and managers.

On a similar note, the emergent field of CDR might open up new possibilities for collaborations with companies and governmental institutions. The CDR debate took off after leading corporations and governmental entities recognized that the recent advancements in technology bring various complex challenges that require a shift in entrepreneurial responsibility (Lobschat et al. 2021). Moreover, as organizations gradually recognize that CDR will shortly turn, similarly to CSR, into a strategic competitive advantage, various businesses show increased interest in the topic. Thus, such organizations are also more willing to collaborate with BISE researchers to obtain valuable knowledge and advantages by being the first ones to introduce and apply CDR in their operations.

Similarly, there might be new opportunities to collaborate with governmental entities that seek to minimize adverse effects of technology use through regulatory frameworks. In this respect, due to its closeness to technological developments and businesses, the BISE community can inform policymakers and contribute towards relevant and meaningful regulations.

\section{Actively Engaging in the CDR Debate}

From a BISE perspective, the CDR concept enables an equitable, participatory, autonomy-respecting, and sustainable development and operation of technology products and services. To materialize this vision, there are various ways and research questions through which the BISE community can contribute to the current CDR debate. 
Below, we highlight only two pressing research directions that need to be addressed as soon as possible.

One essential research direction is the conceptualization and concrete operationalization of CDR. As mentioned previously, the concept of CDR is currently still in its infancy, with few concrete suggestions for action and little guidance on how companies can embrace CDR in their business. In this regard, the practice-driven debate on CDR (United Nations 2016; Thorun et al. 2017) has put forward various norms suitable to promote ethical and responsible management and the use of technology and data. Amongst others, these norms suggest that (1) consumers should have access to essential digital goods and services; (2) consumers should be educated and informed about the perils and consequences of their consumption decisions in the digital world; (3) consumers need access to appropriate information about how their data is collected and handled; (4) consumers' economic interests need to be protected and promoted.

Although the mentioned norms are only exemplary, they highlight that at this stage the CDR concept is too abstract to be implemented directly into practice. Here, the BISE community should focus on conducting research that can clarify and articulate concrete norms and guidelines which enable companies to assume more responsibility in the digital world. Also, the norms put forward by the practice debate are non-exhaustive. For instance, the eco-sustainability issues, and in particular the energy consumption that technology development and use requires, are not reflected in the current state of practice-proposed CDR norms. Here, the BISE community can help expand the CDR concept with currently unconsidered but important facets of corporate responsibility.

After sharpening the CDR concept, subsequent fruitful paths for research emerge from the detailed analysis of the suitability and effectiveness of different CDR measures companies could implement. Recalling that the implementation of CDR can be pursued in many ways and at various levels (Matten and Moon 2008) and practice has typically only limited resources to implement CDR, a successful CDR implementation in practice hinges on companies' ability to pursue CDR measures at levels that are important for key stakeholders involved (Kesavan et al. 2013). Thus, BISE research should investigate the suitability and effectiveness of various CDR activities for different key stakeholder groups in various types of businesses and industries. After all, the pressure to implement CDR in a company and the question to which extent this is possible might depend on the industry in which the company operates, the products and services it markets, or the stakeholders involved. For instance, the extent and measures through which CDR should be implemented in highly digitized industries might significantly differ from those in less digitized ones.

Similarly, in industries in which companies collect and handle sensitive data (e.g., healthcare), the CDR measures will likely vary from industries that operate with less sensitive data (Lobschat et al. 2021). Also, technology implicates different social and ethical dilemmas depending on the stakeholders involved. For example, suppose the stakeholder group of consumers is relevant to a business. In that case, ethical issues related to individual autonomy and human rights concerning fairness (Feuerriegel et al. 2020), discrimination, social exclusion, or stigmatization (Royakkers et al. 2018) are more salient than in constellations where consumers are not a relevant stakeholder for business.

Albeit the research paths mentioned above are not exhaustive, they delineate how the BISE community can play a leading role in shaping the future relationship between humans and technology. After all, since technology permeates almost all aspects of our personal and professional lives, it is now impossible to evade technology use or its consequences. By researching how we can maximize the benefits of digitalization while minimizing its accompanying adverse effects, the BISE community can significantly contribute to a matter of great social and economic relevance.

\section{References}

Agudelo MAL, Jóhannsdóttir L, Davídsdóttir B (2019) A literature review of the history and evolution of corporate social responsibility. Int J Corp Soc Responab 4:1-23

Baird A, Maruping LM (2021) The next generation of research on IS use: a theoretical framework of delegation to and from agentic IS artifacts. MIS Q 45:315-341

Berente N, Gu B, Recker J, Santhanam R (2021) Managing Artificial Intelligence. MIS Q 45:1433-1450

Carroll AB (1991) The pyramid of corporate social responsibility: toward the moral management of organizational stakeholders. Bus Horizons 34:39-48

Elliott K, Price R, Shaw P, et al (2021) Towards an equitable digital society: artificial intelligence (AI) and corporate digital responsibility (CDR). Soc, pp 1-10

Feuerriegel S, Dolata M, Schwabe G (2020) Fair AI: challenges and opportunities. Bus Inf Syst Eng 62:379-384

Herden CJ, Alliu E, Cakici A et al (2021) Corporate digital responsibility. Sustain Manag Forum 29:13-29

Kesavan R, Bernacchi MD, Mascarenhas OA (2013) Word of mouse: CSR communication and the social media. Int Manag Rev 9:58-66

Kröhling A (2017) Digitalisierung - Technik für eine nachhaltige Gesellschaft? CSR und Digitalisierung, 2nd edn. Springer, Heidelberg, pp 31-64

Legner C, Eymann T, Hess T et al (2017) Digitalization: opportunity and challenge for the business and information systems engineering community. Bus Inf Syst Eng 59:301-308 
Lobschat L, Mueller B, Eggers F et al (2021) Corporate digital responsibility. J Bus Res 122:875-888

Matten D, Moon J (2008) "Implicit" and "explicit" CSR: a conceptual framework for a comparative understanding of corporate social responsibility. Acad Manag Rev 33:404-424

Mihale-Wilson CA, Zibuschka J, Carl KV, Hinz O (2021) Corporate digital responsibility: extended conceptualization and empirical assessment. Marrakech. https://aisel.aisnet.org/ecis2021_rp/80

Nofer M, Hinz O, Muntermann J, Roßnagel H (2014) The economic impact of privacy violations and security breaches. Bus Inf Syst Eng 6:339-348

Royakkers L, Timmer J, Kool L, van Est R (2018) Societal and ethical issues of digitization. Ethics Inf Technol 20:127-142

Smith NC (2001) Changes in corporate practices in response to public interest advocacy and actions. Handbook of marketing and society. Sage, Thousand Oaks, pp 140-161
Thorun C, Vetter M, Reisch L, Zimmer AK (2017) Indicators of consumer protection and empowerment in the digital world. Results and recommendations of a feasibility study. https://www. bmj.de/G20/DE/ConsumerSummit/_documents/Downloads/Stu die.pdf?_blob=publication-File\&v=1/. Accessed 14 Oct 2021

United Nations (2016) Data protection regulations and international data flows: implications for trade and development. https:// unctad.org/en/PublicationsLibrary/dtlstict2016d1_en.pdf. Accessed 14 October 2021

van der Aalst WM, Bichler M, Heinzl A (2017) Responsible data science. Bus Inf Syst Eng 59:311-313

Watson RT, Boudreau M-C, Chen AJ (2010) Information systems and environmentally sustainable development: energy informatics and new directions for the IS community. MIS Q 34:23-38 